\title{
ENTENDENDO O ANARQUISMO metodológico de P. K. Feyerabend
}

\author{
JoÃo Batista Cichero Sieczkowski*
}

\begin{abstract}
RESUMO
Por volta de 1975 a filosofia da ciência foi assombrada pela publicação do irreverente livro de P.K. Feyerabend "Contra o Método" ("Against Method") que ousava defender a tese de que a ciência não progredia amarrada por uma metodologia determinada e nem mesmo era uma atividade humana racional como positivistas e falseacionistas entendiam. 0 objetivo deste artigo é mostrar quais são as teses de Feyerabend que abalaram a maneira de pensar dos epistemólogos das ciências. Para isso confrontamos as teses de Feyerabend com os positivistas, falseacionistas e com o relativismo pragmático de T. Kuhn. 0 resultado foi um mergulho no ceticismo. Do dogmatismo de positivistas e falseacionistas para o relativismo de Kuhn e acabando no ceticismo de Feyerabend em respeito a atividade científica.
\end{abstract}

Palavras-chaves: Método; ciência; racionalidade; progresso; teoria

\section{FALTA O TÍTULO EM INGLÊS}

\begin{abstract}
Around 1975 the philosophy of science was haunted by the publication of the irreverent book by PK Feyerabend "Against Method" ("Against Method") that dared to defend the thesis that science did not progress bound by a determined methodology and was not rational human activity as positivists and falsificationists
\end{abstract}

* IELB - Igreja Evangélica Luterana do Brasil. joao.bcs1961@gmail.com

Revista Páginas de Filosofia, v. 9, n. 2, p. 147-164, jul.-dez. 2020 
understood. The purpose of this article is to show which are the Feyerabend's theses that have shaken the way of thinking of the epistemologists of the sciences. For that, we confront Feyerabend's theses with the positivists, falseacionistas and with the pragmatic relativism of T. Kuhn. The result was a dip in skepticism. From the dogmatism of positivists and falsificationists to Kuhn's relativism and ending in Feyerabend's skepticism regarding scientific activity.

Keywords: method; science; rationality; progress; theory

\section{INTRODUÇÃo}

P. Feyerabend pertence aqueles filósofos que se denominam defensores de uma "Nova Filosofia da Ciência", junto com Kuhn e I. Lakatos. Em verdade, são os filósofos da ciência externalistas, isto é, aqueles que acreditam que o problema central da Filosofia da Ciência chegará a um resultado mais objetivo se considerarmos o aspecto histórico e psicológico (Kuhn) e, até mesmo, muitos outros aspectos (Feyerabend), como o estético, por exemplo.

Feyerabend não é nada sistemático. É irreverente e irônico em suas constatações a respeito de seus adversários. No entanto, vamos tentar ser sistemáticos, obedecendo a seguinte estrutura: (1) As teses principais do pensamento de Feyerabend; (2) A crítica de Feyerabend ao Positivismo Lógico; (3) A crítica de Feyerabend a Popper; (4) A crítica de Feyerabend a Kuhn.

\section{AS teses PRincipais do PENSAMENTO DE FEYERABENd}

(a) Em primeiro lugar, é bastante interessante definir o que devemos entender por ANARQUISMO EPISTEMOLÓGICO. Segundo Feyerabend, o anarquismo epistemológico é uma maneira de indicar a "direção" do progresso da ciência. É, em verdade, uma alternativa em relação aqueles que pensam que para falar do progresso na ciência precisamos fazer jus a ordem e a lei. Ora, para Feyerabend não importa o controle, o estabelecimento da direção do progresso, mas muito antes pelo contrário, o que importa é o efetivo progresso. Para Feyerabend, não importa a VALIDADE do conhecimento que orientará o progresso, porém, o que importa é a PRODUÇÃO do conhecimento científico. E o conhecimento científico pode ser constatado como progressivo de 
diversas maneiras. Tudo colabora para o progresso da ciência. Diz Feyerabend:

Não há por que temer que a decrescente preocupação com lei e ordem na ciência e na sociedade - que é característica desse tipo de anarquismo - venha conduzir ao caos. 0 sistema nervoso humano é demasiado bem organizado para que isso venha a ocorrer (CM, p.23).

Mas, é claro que Feyerabend terá ainda que dizer como o cientista pode constatar o seu avanço, a sua evolução na produção do conhecimento científico. Em síntese: o anarquismo epistemológico se define pela liberdade de produzir o conhecimento científico, sem determinações constrangedoras.

(b) No anarquismo epistemológico, o cientista não inibe o progresso da ciência. Vale tudo. Como diz Feyerabend: “... as violações são necessárias para o progresso” (CM, p. 29). A metodologia dedutiva, pelo seu caráter antecipatório, é prejudicial ao progresso da ciência. A argumentação lógica nos coloca dentro de limites. Todas as suas conclusões estão contidas nas premissas que são manipuladas por regras pré-estabelecidas. 0 progresso é direcionado. Mas, o que fazer com descobertas acidentais que fogem aos padrões lógicos, aos limites da argumentação? Eliminá-los? Ignorá-los? "Partimos de uma firme convicção, contrária a razão e à experiência da época" (CM, p. 33). Aí está a atitude fundamental do anarquista. Cada cientista vê a realidade como quer, a descreve como quer. Não há uma única maneira de ler a natureza. Não há uma uniformidade em descrever a natureza. 0 que é o progresso para o positivista, poderá ser perfeitamente contrário para o falseacionista. Todas maneiras de explicar o progresso na ciência são possíveis. Não há uma única maneira de explicá-la. Diz Feyerabend:

Os que tomam do rico material da história, sem a preocupação de empobrecê-lo para agradar a seus baixos instintos, a seu anseio de segurança intelectual (que se manifesta como desejo de clareza, precisão, "objetividade", "verdade"), esses vêem claro que só há um princípio que pode ser defendido em TODAS as circunstâncias e em TODOS os estágios do desenvolvimento humano. É o princípio: TUDO VALE (CM, p. 34). 
(c) A ciência progride contra-indutivamente. Ora, o que significa dizer que TUDO VALE para a ciência progredir? Podemos propor a hipótese que quisermos para estabelecer os contornos de nossa teoria. $\mathrm{Na}$ atitude anarquista de que tudo vale, iremos preferir sempre as hipóteses que não se ajustam às nossas teorias, que acreditamos serem aceitas e confirmadas. Em segundo lugar, iremos preferir hipóteses que não se acomodem aos fatos bem estabelecidos. Dessa maneira, iremos contemplar um oceano, um mar de alternativas que estavam fora de nosso controle, de nosso alcance. Isso é, especificamente, progredir contra-indutivamente. 0 cientista deve "tornar forte, o argumento fraco." Só podemos ver as limitações das metodologias científicas operando contra-indutivamente. Isso nos leva a tese seguinte.

(d) A PROLIFERAÇÃO de teorias indiscriminadamente ajuda no progresso da ciência. Ora, o princípio da proliferação de teorias de Feyerabend diz que "inventar e elaborar teorias que sejam inconsistentes com o ponto de vista aceito, ainda que se diga no caso de que este último estiver altamente confirmado e geralmente aceito." Este é o princípio do pluralismo teórico de Feyerabend. A proliferação de teorias abre para o cientista um mundo de alternativas e desenvolve uma variedade de opiniões. A atitude do cientista é de compreender que, em maior ou menor grau, todas as opiniões participam da evolução gradual da ciência, mesmo aquelas e, principalmente, aquelas que tratamos ou que o cientista trata como NÃO-científicas. Feyerabend ressalta que esta atitude anarquista é a que está mais de acordo com uma atitude humana, com a natureza humana. A natureza humana se caracteriza, acima de tudo, por ser imprevisível. E, Feyerabend está muito bem consciente disso. Diz Feyerabend: "Qualquer ideia, embora antiga e absurda é capaz de aperfeiçoar nosso conhecimento. A ciência ABSORVE TODA a história do pensamento e a utiliza para o aprimoramento de cada teoria" (CM, 65).

Um outro aspecto dessa mesma tese é que o pluralismo teórico procurará comparar teorias e não comparar a teoria com experiências, dados ou fatos. 
(e) A ciência é uma entre muitas FORMAS DE VIDA. Ora, este conceito não é original. A sua derivação é do Wittgenstein das INVESTIGAÇÕES FILOSÓFICAS (1953). Diz Wittgenstein "o que tem que ser postulado, o que é dado, poderíamos dizer, são as FORMAS DE VIDA" (IF, p. 238/601). Mas o que significa FORMAS DE VIDA? Falar de formas de vida em epistemologia é estabelecer as condições gerais em que é possível falar-se da compreensão da realidade, enquanto que falar de formas de vida em filosofia é estabelecer as formas peculiares de que se estrutura a compreensão em determinados contextos. Diz Peter Winch, interpretando Wittgenstein:

enquanto as filosofias da ciência, da arte, da história, etc terão a tarefa de elucidar as naturezas peculiares dessas formas de vida chamadas "ciências", "arte", etc..., a epistemologia tentará elucidar o que está envolvido na noção de forma de vida com tal (ICS, 47-8).

A contribuição de Wittgenstein para esta análise epistemológica consistiu em dois pontos: (a) a análise do conceito de "seguir uma regra"; (b) e a descrição da espécie peculiar de concordância interpessoal que isto envolve.

Para Feyerabend, a ciência é uma entre várias formas de vida e, não necessariamente a melhor. Outras formas seriam, por exemplo, o mito e a poesia, a estética, etc... Feyerabend alerta para o fato de que o racionalista crítico (Falseacionista) desconsidera tais formas de vida, taxando-as como irracionais. Estão na verdade a bloquear o progresso na ciência. A abertura para outras formas de vida se faz aceitando um pluralismo teórico e um pluralismo de formas de vida. Constitui-se uma outra racionalidade. Feyerabend, só não consegue escapar da crítica de que dificilmente poder-se-ia mostrar como uma forma de vida é melhore do que outra. A conclusão é que todas as formas de vida são boas, do ponto de vista teórico. 0 resultado é o ceticismo e o relativismo. Como pode a ciência resolver e absorver toda classe de problemas e todas formas de vida?

(f) A recusa da distinção entre contexto de descoberta e contexto de justificação em Feyerabend. 
Por contexto de descoberta devemos entender o modo como o pensador descobre seu teorema, ou, melhor ainda, é a forma de como são subjetivamente realizados os processos de pensamento. No máximo, disso resulta uma psicologia da descoberta.

Por contexto de justificação deveremos entender uma reconstrução racional do processo de aquisição do conhecimento científico expresso em uma linguagem adequada, sua comunicação e, consequentemente, sua crítica, ratificação ou retificação experimental, apreciação de sua estruturação lógica interna, etc...

Em resumo: o contexto de justificação diz respeito a forma de como os processos de pensamento são comunicados a outras pessoas (intersubjetividade). Foi Hans Reichenbach em 1961 que primeiro fez essa distinção.

Os defensores de uma lógica interna no empreendimento científico como os positivistas e Popper, com algumas ressalvas, se encaixam no contexto da justificação, enquanto que os defensores de uma lógica externa ao empreendimento científico como Kuhn, Feyerabend e I. Lakatos apostam no contexto de descoberta.

Especificamente, a posição de Feyerabend é a recusa em aceitar o contexto de justificação. Segundo Feyerabend, fatores extra científicos influem e devem influir decisivamente no empreendimento científico. 0 progresso da ciência não pode ser determinado apenas por um contexto de justificação, mas o progresso na ciência deve levar em conta contextos de descoberta com o objetivo de serem e apresentarem contra-exemplos e contra-regras a teorias que querem dominar o âmbito de explicação da ciência.

Feyerabend retrata seu repúdio ao contexto de justificação na seguinte passagem do seu livro CM: "A separação entre a história de uma ciência, sua filosofia e a ciência mesma desaparece no ar, o mesmo acontecendo com a separação entre ciência e não ciência” (CM, 68). Ora, se não precisa haver separação entre ciência e não-ciência esfumaça-se o contexto da justificação. A razão de não haver separação entre ciência e não-ciência é o cérebro, o sistema nervoso da FC de Feyerabend. Acredita Feyerabend que a ciência é uma forma de vida entre tantas. Apesar do suposto controle que podemos exercer sobre 
os enunciados e teorias científicas podemos muito bem admitir a contribuição significativa de outras formas de vida na determinação dos limites e resultados de teorias científicas. Essa face até agora desconhecida e negada por filósofos e cientistas pode muito bem fazer fluir o progresso na ciência. Vale tudo, se com isso se consegue o progresso, diz Feyerabend. Diz Peter Winch:

Segue-se que não se pode aplicar critérios de lógica aos modos de vida social como tais. Por exemplo, ciência é um modo de vida e religião um outro; cada um tem critérios de inteligibilidade peculiares. Assim dentro da religião ou da ciência, as ações podem ser lógicas ou ilógicas; em ciência, por exemplo, seria ilógico recusar submeter-se aos resultados de um experimento levado a efeito adequadamente; e em religião seria ilógico supor-se que alguém podia apostar a sua própria força contra a de Deus, e assim por diante. Mas não podemos razoavelmente dizer que seja a prática da ciência ou da religião lógicas ou ilógicas; ambas são não-lógicas. (ICS, p. 97-8).

É dessa mesma maneira que ocorre com as diversas formas ou modos de vida. Dizer que um modo de vida é mais importante do que outro, ou dizer que uma teoria é mais importante do que outra, é reduzir e restringir drasticamente o progresso na ciência no entender de Feyerabend.

Feyerabend propõe um "culturalismo" em lugar de um "naturalismo" de tipo positivista. Os aspectos subjetivos e principalmente estéticos podem contribuir para a ciência, para o seu progresso. Toda teoria tem um risco de subjetividade. Portanto, toda teoria nunca possuirá um apoio completo do ponto de vista experimental. Isso até um falseacionista concorda e está no cerne de qualquer crítica contra o positivismo lógico.

\section{A Crítica de feyerabend ao Positivismo lógico}

$\mathrm{O}$ anarquismo epistemológico de Feyerabend começou a se estruturar por meio de uma crítica à METODOLOGIA positivista. Todo positivista lógico sempre se preocupou com o contexto de justificação do empreendimento científico. Neste sentido, para o positivista sempre houve grande importância o fato de que a ciência deveria elucidar-se, mesmo o seu 
progresso, por uma explanação da lógica interna e isso sempre poderia ser feito - esse controle - por uma manipulação simbólica, por um formalismo. Assim, a ciência deveria ter a sua própria linguagem teórica e observacional de caráter unificador e universal inerente a ela própria.

A concepção positivista de progresso na ciência é de caráter cumulativo, isto é, sem conflitos entre Teoria1 e a Teoria2, e sem revoluções. Feyerabend aponta corretamente que é somente nestas circunstâncias que poder-se-ia "garantir" uma derivação lógica mediante REDUÇÃO. Uma redução lógica da matemática, por exemplo, só seria possível - se assim o fosse - com essa concepção de progresso. 0 outro aspecto de "garantia" à redução lógica seria, para o positivista, a não mudança de significado dos termos de uma teoria a outra. A mudança de contexto não implicaria necessariamente em mudança de significado dos termos de uma teoria. Isso poderia "garantir" uma linguagem unificada e universal para a ciência.

Ora, uma vez que as teorias estabelecem competição entre si, a concepção de progresso positivista fica ameaçada e o programa reducionista esfacela-se. Feyerabend critica justamente em E. Nagel e K. Hempel esse reducionismo lógico. Diz Nagel a respeito da Redução: “O objetivo da redução é mostrar que as leis, ou os princípios gerais da ciência secundária são simplesmente CONSEQÜÊNCIAS LÓGICAS dos supostos da ciência primária" (RC, 46). O segundo pressuposto é assim expresso por Nagel: "os significados são invariantes a respeito do processo de redução” (RC, 47). Segundo Feyerabend, a prática científica desmente estes dois pressupostos aceitos pelos positivistas.

K. Hempel, outro positivista, aponta para o detalhe de que a EXPLICAÇÃO é uma consequência lógica e, que os significados não se alteram no processo de explicação. Como resume bem Feyerabend: A) A redução e a explicação são (ou deveriam ser) por derivação; B) Os significados dos termos (observacionais) são invariáveis tanto no que diz respeito a redução como na explicação.

\section{Crítica de feyerabend a Popper}

Há dois aspectos que P. Feyerabend critica na filosofia popperiana (falseacionismo): a) a rejeição dos aspectos subjetivos do empreen- 
dimento científico; b) a rejeição da incomensurabilidade das teorias científicas.

(a) Feyerabend valoriza os aspectos subjetivos da atividade científica. Com isso acredita, principalmente, em atacar o FORMALISMO dos positivistas lógicos, projeta este rótulo sobre o falseacionismo com todo seu peso. Feyerabend argumenta de modo a considerar Popper um positivista sofisticado. Mas qual a justificativa que Feyerabend usa para introduzir a subjetividade na ciência? Feyerabend diz que teorias de caráter universal sempre transcendem a observação, os dados observacionais de um determinado momento. Dessa forma, a observação, nunca apoiará COMPLETAMENTE uma teoria universal. As teorias científicas nascem, crescem e morrem em meio a um OCEANO DE ANOMALIAS. Tal afirmação não é de Feyerabend, Kuhn e Lakatos já teriam afirmado o mesmo.

A justificativa de Feyerabend em introduzir aspectos subjetivos à ciência utiliza-se de um princípio aceito pelos próprios falseacionistas, a saber, uma teoria nunca pode ser confirmada completamente. Uma teoria nunca terá um apoio experimental que lhe possa revestir ou envolvê-la totalmente. Mas bastará essa concepção par introduzir-se a subjetividade na ciência? Como poderá a ciência, dessa maneira, comunicar os seus resultados? A intersubjetividade da ciência não estará ameaçada? A segunda justificativa que Feyerabend usa para introduzir a subjetividade na ciência, parte novamente de um aspecto do falseacionismo. $\mathrm{O}$ aspecto do falseacionismo que Feyerabend parte para colocar a subjetividade como elemento de destaque na ciência é a FALIBILIDADE que sempre está presente em todo empreendimento humano e, também está na ciência. Isso o falseacionista não nega.

Em conclusão: Feyerabend nos diz que estes dois aspectos juntos, implicam a liberdade do teórico perante a experiência, liberdade que vem restringida pela tradição (aspectos sociais e culturais), a idiossincrasia do indivíduo (aspectos subjetivos), pelos formalismos e uso da linguagem (problema de terminologias e tecnicismos), conjunto de crenças metafísicas (Kuhn) e inclusive por motivos estéticos (Galileu perante Kepler). 
Em verdade, Feyerabend ataca mais o positivismo lógico do que o falseacionismo quando pretende dar importância a subjetividade na ciência. A razão disso é a de que tal ideia já está sendo, de alguma maneira, incorporada com todo cuidado na concepção de ciência. 0 reducionismo eliminativo dos positivistas se sente muito mais atingido por essa crítica.

(b) Feyerabend quer também valorizar a incomensurabilidade das teorias científicas. Esse aspecto não é novo. Kuhn reclama, e com razão, a paternidade dessa ideia. A incomensurabilidade das teorias serve, para Kuhn, com o fim de explicar o historicismo da ciência e as revoluções científicas. Feyerabend apoia a incomensurabilidade das teorias nas constantes mudanças de perspectiva que ocorre dentro da ciência devido a fatores externos como os fatores históricos, sociológicos, psicológicos e estéticos. Nada há de novo, portanto!

0 falseacionismo com razão atribui a concepção feyerabendiana as características seguintes: (a) irracionalismo; (b) historicismo; (c) relativismo. 0 fim de tudo é que cada qual se fecha em sua posição. Há hoje o impasse!

A incomensurabilidade de teorias científicas é derivada de Wittgenstein. As noções de JOGOS DE LINGUAGEM, e, REGRAS que os dirigem, estão na base da incomensurabilidade das teorias científicas. Ora, podemos falar de jogos de linguagem na medida em que entendemos a forma de usar os termos, isto é, as palavras. Assim como um operário usa o martelo para martelar; assim como usa o serrote para serrar; assim como o jogador usa a bola para jogar; assim também, nós todos - incluindo os cientistas - usamos a linguagem, jogando com os termos. Dessa forma, não há uma única função de uma expressão, de um termo de linguagem. A diversidade de usos e funções dos termos ou expressões permite uma riqueza de jogos de linguagem, que nada possuem de comum, a não ser um aparente ar de familiaridade. Estes termos se cruzam, se permutam e se combinam quase que infinitamente, demonstrando assim toda uma complexidade e diversidade. Os jogos de linguagem apenas podem entrar em comparação se CONSEGUIRMOS detalhar os diversos usos e funções dos termos contidos na complexidade de jogos existentes. 
Bem, imaginemos a comunidade científica e os cientistas. Aí ocorre diversos e complexos jogos de linguagem a cada momento. Para afirmar uma teoria científica o cientista se utiliza desses jogos de linguagem. Jogar com as palavras é a maneira de convencer as pessoas. E isso ocorre no meio da comunidade científica.

Mais ainda, todas teorias envolvem termos, palavras e expressões. Jogar com estas palavras significa convencer nosso opositor, persuadi-lo e mudar sua perspectiva da realidade (GESTALT). Conforme a linguagem que o cientista utiliza - o jogo de linguagem escolhido - a sua teoria pode o não pode ganhar credibilidade. A lógica é um entre tantos jogos de linguagem e, não necessariamente o mais convincente ou persuasivo. Aliás, não nem um pouco persuasivo!

Em síntese: a mensurabilidade de teorias não se restringe somente a instrumentos de medição, à lógica formal reducionista e eliminativa, mas há algo decisivo: o jogo da linguagem. É a escolha do jogo de linguagem que torna a teoria científica incomensurável em sua escolha. Por que preferir Teoria2 do que a Teoria1? A linguagem torna a realidade diferente na medida em que apenas a representa, e a representa de diversas maneiras que nem sempre podem ser ditas como "racionais".

O resultado é o RELATIVISMO ABSOLUTO do pensamento de Feyerabend e de Wittgenstein. Se "tudo vale", então na arte vale a mentalidade comercial. "Tudo vale (na arte) se há saída comercial." Do dogmatismo absoluto do positivismo lógico desaguamos no relativismo absoluto. 0 que responder a essa situação criada pela própria FC de Feyerabend?

A noção de incomensurabilidade quer criticar a objetividade sem sujeito e a história sem sujeito, mas para firmar-se precisa de parâmetros, ou seja, critérios alheios ao sujeito. Daí o retorno a uma objetividade e a uma história da ciência desprovida de sujeito cognoscente.

A crítica contra o falseacionismo está descrita no capítulo XV do livro CM de Feyerabend. A crítica que agora nos referirmos vai além dos aspectos que abordamos. Nós iremos referir ao ARGUMENTO DA ILUSÃO EPISTEMOLÓGICA de Feyerabend contra Popper (falseacionismo).

Se considerarmos a Teoria1 e a Teoria2 diremos que a absorção do conteúdo empírico de T1 por T2 nunca é completa. Haverá uma 
parte que pertencerá a T1 e T2, mas haverá, também, uma parte de T1 que SERÁ EXCLUÍDA. Assim:

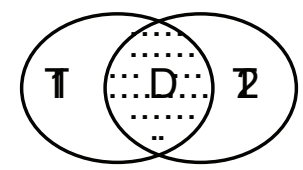

"D" é o domínio comum de T1 que se adaptou a METODOLOGIA de T2. Portanto, somente uma parte de T1 interessa a T2. 0 progresso determinado assim é insuficiente. Diz Feyerabend, aqueles conteúdos empíricos de T1 que são comuns a T2" ... foram distorcidos de maneira a se acomodarem às novas linhas dominantes. "Essa ilusão é a responsável por teimosamente persistir a exigência de conteúdo maior." (CM, 277)

0 que desgosta Feyerabend é que, tudo aquilo que não se adapte a METODOLOGIA CIENTÍFICA DOMINANTE É EXCLUÍDO da participação do progresso da ciência como anticientífico. No entender de Feyerabend, se Popper tivesse optado pela absorção total e completa de T1 por T2, isso seria uma ilusão ainda pior que, na PRÁTICA CIENTÍfICA NÃO SE REALIZA. Assim temos:

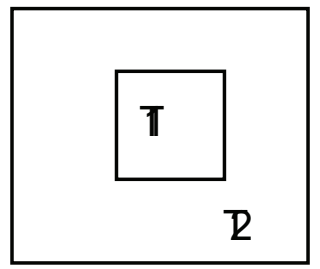

Isso seria: T2 afirma tudo o que T1 possui, todo o seu conteúdo empírico e mais um pouco, que T1 não teria afirmado. Sintetiza bem John Watkins em seu artigo "o enfoque popperiano do conhecimento científico." (cf. PRC, 31-48)

"Seja T a melhor teoria em seu campo em UM MOMENTO DETERMINADO. Que teria que fazer uma nova teoria T' para supor um CLARO AVANÇO_(progresso) a respeito de T? As condições PREVIAS de tal avanço são estas:

1. Que T' responda toda à questão empírica a que $\mathrm{T}$ pode responder e o faça, pelo menos, com igual precisão. 
2. Que T' responda algumas questões empíricas para as que $\mathrm{T}$ não tem_resposta ou a tem em menor precisão.

3. Que T' tenha correções observacionalmente discerníveis de algumas das respostas dadas por $\mathrm{T}$, e não somente nas áreas onde $\mathrm{T}$ tem tropeçado com dificuldades empíricas, senão também nas áreas em que $\mathrm{T}$ tem sido, até então, bem corroborada.

Em resumo, T' DEVERIA IR MAIS ALÉM que T e DEVERIA CORRIGI-LÁ em nível empírico." (PRC, 40-1)

Assim, uma T2 ou T' possui três partes: (a) uma região de conteúdo empírico que vai além de T1 ou T; (b) uma região de conteúdo empírico que é comum tanto a T2 com a T1; (c) e uma região de conteúdo empírico que é usado para revisar o conteúdo empírico de T1. Por sua vez T1 ou T possui duas partes; (a) a região de conteúdo empírico que é comum a T2; (b) e a região de conteúdo empírico que foi REVISADA por T2.

No entender de Feyerabend essa região de conteúdo empírico revisada por T2 é excluída por não se adaptar a metodologia de T2, que T2 impõe sobre T1. Ora, mas como é por que ocorreu essa mudança de orientação metodológica? A metodologia de T1 que antes era científica, passou a ser anticientífica; e a metodologia de T2 passou a ser científica.

Para Feyerabend, os cientistas forçam uma adaptação de T2 para deixar estabelecido que houve progresso, mas se também contrastássemos essa região de conteúdo empírico anticientífico com T2, haveria um progresso muito mais significativo.

Vejamos o diagrama de J. Watkins:

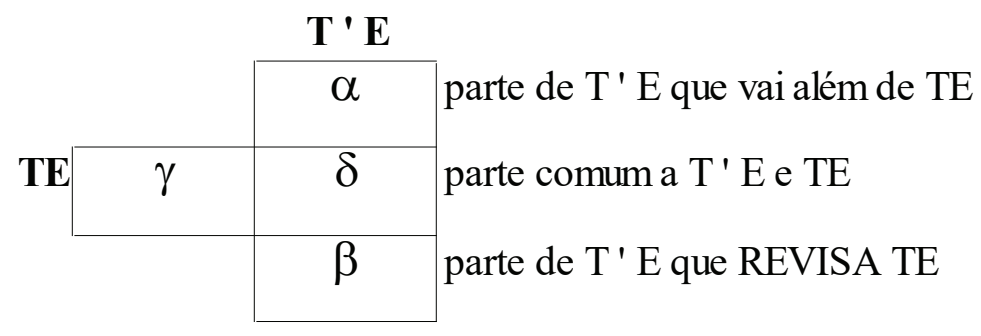

parte de TE que é

revisada por T 'E

Revista Páginas de Filosofia, v. 9, n. 2, p. 147-164, jul.-dez. 2020 
A ilusão epistemológica reside especificamente, segundo Feyerabend, em que consideramos como falseacionistas que nos dá um conteúdo empírico além de TE. Isso pode ser desmentido se contrastarmos a região que foi excluída pela metodologia de T' E com a região de T' E. Certamente, o AVANÇO, o progresso significativo que estaria em não seria tão notório.

Em conclusão: para Feyerabend toda metodologia científica objetiva diferenciar a ciência como empreendimento humano de outros empreendimentos como arte, religião, mito, cabala, etc... Ora, se a metodologia científica falseacionista pudesse determinar como a ciência progride, de um ponto de vista lógico, a diferença ficaria evidente. A demarcação teria seu caráter de necessidade justificado. 0 fato de que o falseacionista encontre na ciência um empreendimento que objetiva resolver problemas cruciais para a sobrevivência humana é que deveria distinguir a ciência de outras pseudociências como a astrologia, e de outras atividades "inferiores" como a arte, religião, etc...

\section{Crítica de Feyerabend a T. S. Kuhn}

Feyerabend não acredita que Kuhn tenha se diferenciado de Popper quanto a seguir uma metodologia e de impô-la sobre a comunidade científica.

Todas as vezes que leio Kuhn, perturba-me a seguinte pergunta: estamos aqui diante de PRESCRIÇÕES METODOLÓGICAS que dizem respeito ao cientista como há de proceder; ou diante de uma DESCRIÇÃO, isenta de qualquer elemento avaliativo das atividades geralmente rotuladas de "científicas? (CDC, 245).

Supondo que Kuhn quissesse DESCREVER o processo de avanço da ciência, isto é, que Kuhn tenha se dedicado a descrição de acontecimentos históricos e instituições influentes e, isto foi principalmente realizado pelo esboço de sua ideia de ciência normal. Feyerabend entra aqui com sua crítica. Segundo Feyerabend, não há diferença entre um cientista que faz ciência normal e um componente do crime organizado. 0 papel do cientista individual pode ser projetado identicamente sobre o papel executado pelo arrombador de cofres individual. 0 
arrombador de cofres, tal qual como o cientista normal, se detém em conhecer somente o cofre que está querendo abrir. Ele conhece todas as particularidades DESTE cofre. Assim é o cientista normal que só conhece um tipo de teoria nessa época (um paradigma) e julga por meio deste todas as demais teorias. 0 arrombador de cofres sabe quais instrumentos e ferramentas que deverá usar para abrir o cofre. O cientista normal sabe que os instrumentos científicos que servem para testar teorias; se caso o arrombador de cofres não concretizar sua tarefa, a culpa recairá sobre ele. É o arrombador de cofres que não terá competência de exercer sua profissão. Por outro lado, se o cientista normal não consegue responder às questões colocadas (quebra-cabeças) pela natureza, o fracasso é do cientista e não do paradigma que não sabe respondê-las, nem mesmo dos instrumentos científicos. Segundo Feyerabend, para Kuhn, o malogro da consecução reflete-se, por certo, "na competência do (arrombador de cofres) aos olhos dos colegas de profissão" de modo que "é o indivíduo (o arrombador de cofres) e não a teoria vigente (do eletromagnetismo, por exemplo) que está sendo posto à prova", "só o profissional é censurado, não os seus instrumentos" - e assim podemos continuar passo a passo, até o derradeiro item da lista de Kuhn." (CDC, 248)

Onde falhou Kuhn? No entender de Feyerabend Kuhn não discutiu a FINALIDADE DA CIÊNCIA. Todo arrombador de cofres tem uma finalidade: ganhar dinheiro. Qual é a finalidade do cientista em fazer ciência?

Supondo que para Kuhn a finalidade da ciência seja a mudança de paradigma - a GESTALT, portanto. Como ocorre essa Gestalt? Pela aceitação do princípio de proliferação em que é introduzido e expresso alternativas a teoria dominante, o que seria uma METODOLOGIA RACIONAL que é imposta sobre a ciência e os cientistas, OU a mudança de Gestalt ocorre quando os cientistas estão estafados, entediados e frustrados com o paradigma dominante ( do período de ciência normal ) que não responde aos seus anseios? Kuhn não se pronuncia quanto a estas questões.

Por outro lado, Feyerabend enumera três problemas metodológicos em Kuhn: 
(1) Em Kuhn com a mudança de gestalt - que caracteriza o período de Revolução Científica - dificilmente poderia seguir-se algo de MELHOR. Não há garantia de que algo de MELHOR poderia seguir-se após a GESTALT, porque os paradigmas são incomensuráveis. O que significa seguir-se algo de MELHOR? Entendido no contexto, Feyerabend quer dizer que da mudança de Gestalt dificilmente decorreria um PROGRESSO, uma evolução da ciência. Mesmo que supuséssemos tal avanço não poderíamos constatá-lo porque os paradigmas envolvidos no momento de Gestalt são incomensuráveis, isto é, não podem ser medidos.

(2) Em segundo lugar, Kuhn não responde à questão: como procedem os cientistas? Em vez disso se preocupa em responder o como (ele) deseja que o cientista devesse proceder. Ora, para Kuhn um cientista abandona o ataque a um paradigma por não possuir argumentos contra ele. Segundo Feyerabend, não é por falta de argumentos que o cientista abandona o paradigma. Para Feyerabend, outros aspectos, como por exemplo, a frustração ou até mesmo a morte dos representantes de um paradigma, seriam maneiras de justificar o abandono dos cientistas de um determinado paradigma. E isso, segundo Feyerabend, está mais de acordo com a prática científica.

O que fica claro é que, Kuhn não explica o que ocorre e como procedem os cientistas na troca de um período de ciência normal para um período de Revoluções Científicas. "Que é o que acontece no fim de um período normal?" (CDC, 254) e, ainda mais importante: "Se a ciência normal é de FACTO tão monolítica quanto o quer Kuhn, DE ONDE VÊM AS TEORIAS CONCORRENTES?" (CDC, 255) Da mudança do estilo argumentativo do cientista? Se é assim, para Feyerabend isso é um amor exagerado pela METODOLOGIA. Kuhn "Disse, portanto, que os cientistas criam revoluções de acordo com o nosso modelozinho metodológico e NÃO seguindo inexoravelmente um paradigma e abandonando-o de repente_quando os problemas se agigantam." (CDC, 256)

(3) 0 terceiro problema metodológico de Kuhn, que atesta que Kuhn estava mais interessado em fornece uma metodologia à ciência do que libertá-la dessas metodologias, é que a ciência normal de Kuhn não 
é um FATO HISTÓRICO. A razão dessa tese é que, como o próprio Kuhn afirmou, anomalias ocorrem em qualquer momento da história de um paradigma e, até mesmo em períodos de ciência normal. Sendo assim, as anomalias já em período de ciência normal dão início ao surgimento de teorias alternativas ao paradigma dominante. Isso mostra-nos que a ciência normal não existe. Vivemos em um grande oceano de anomalias.

Em síntese, diríamos que os argumentos de Feyerabend contra Kuhn são os seguintes: (a) falta da precisão em definir a finalidade da ciência; (b) a questão do abandono do paradigma dominante pelo cientista: é algo LÓGICO ou não-lógico? (c) É difícil precisar se ALGO DE MELHOR se seguirá de uma mudança de paradigma - Gestalt; (d) A ciência normal não existe na história da ciência.

Em conclusão: Se ainda não ficou claro, a noção de progresso na ciência para Feyerabend está expressa no seu dito "Tudo vale". Como deveremos compreender esse dito? É sobre dois princípios: o de proliferação de teorias, que significa que "não há necessidade de suprimir nem o mais estranho produto do cérebro humano" (CDC, p.260). Portanto, se tratam de teorias alternativas que são verdadeiras anomalias ao paradigma dominante pelas suas estranhas e bizarras predições e explicações. 0 segundo princípio: tenacidade, que significa o cientista seguir as suas inclinações e desenvolvê-las. No entanto, surge a pergunta: aceitar essa noção de progresso, fundamentada em princípios, não é aceitar ou submeter-se a uma regra? Não é aceitar uma metodologia? Todo anarquismo é, de certa forma, auto refutador porque a regra é "Tudo vale", e devemos jogar com ela e a partir dela.

\section{REFERÊNCIAS}

CM FEYERABEND, P. Contra o método. Rio de Janeiro: Francisco Alves, 1985.

ERC KUHN, T.S. A estrutura das revoluções científicas. São Paulo: Perspectiva, 1987.

CDC LAKATOS, I. e MUSGRAVE, A (org.). Crítica e o desenvolvimento do conhecimento. São Paulo: Cultrix, 1979.

PRC RADNITZKY, G. et alii. Progreso y racionalidad en la ciencia. Madrid: Alianza, 1982.

ICS WINCH, P. A ideia de uma ciência social. São Paulo: Editora Nacional, 1970. 
IF WITTGENSTEIN, L. Investigações filosóficas. Lisboa: Fundação Calouste Gulbenkian, 1987.

RC EPSTEIN, I. Revoluções científicas. São Paulo: Ática, 1988. 